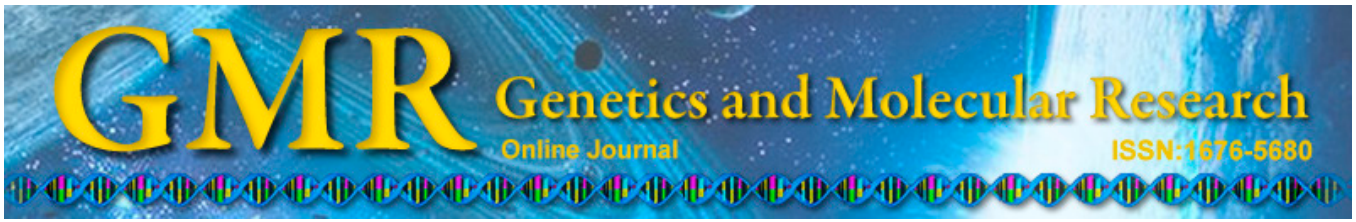

Short Communication

\title{
Screening for fragile $X$ syndrome in males from specialized institutions in the northeast region of Brazil
}

\author{
M.T.M. Viveiros' ${ }^{1}$ M.D.C. Santos' ${ }^{2}$ J.M. Dos Santos ${ }^{3}$, D.M. Viveiros ${ }^{4}$, \\ M.R.M. Cavalcante ${ }^{1}$, A.J.M. Caldas ${ }^{1}$ and M.M.G. Pimentel ${ }^{3}$ \\ ${ }^{1}$ Departamento de Enfermagem, Universidade Federal do Maranhão, São Luís, \\ MA, Brasil \\ ${ }^{2}$ Centro de Pesquisa Clínica, \\ Hospital Universitário da Universidade Federal do Maranhão, São Luís, MA, \\ Brasil \\ ${ }^{3}$ Departamento de Genética, Universidade do Estado do Rio de Janeiro, \\ Rio de Janeiro, RJ, Brasil \\ ${ }^{4}$ Centro Latinoamericano de Estudios Humanos, Punta Del Este, Maldonado, \\ Uruguai
}

Corresponding author: M.T.M. Viveiros

E-mail: viveirosteresa@ig.com.br

Genet. Mol. Res. 14 (2): 6897-6905 (2015)

Received December 8, 2014

Accepted April 28, 2015

Published June 18, 2015

DOI http://dx.doi.org/10.4238/2015.June.18.32

\begin{abstract}
The objective of this study was to perform a study of fragile X syndrome (FXS) in São Luís, Maranhão, in males residing in five specialized institutions. Two hundred thirty-eight males with intellectual disability of unknown etiology participated in this study. Blood samples were processed and stored until DNA extraction. Screening for FMR1 gene mutations was performed using non-isotopic polymerase chain reaction amplification and DNA sequencing using an ABI Prism 3130 automated sequencer. Two individuals $(0.84 \%)$ were positive for FMR1 mutations. One had a mutation due to expansion of the CGG
\end{abstract}


repeat beyond normal levels and the other had a deletion in exon 1 of the FMRl gene, which was confirmed by sequencing. Both probands were over 18 years old, which demonstrates the late diagnosis of the condition in these individuals and reinforces the need to implement effective programs for early diagnosis of FXS in the state of Maranhão. We found that FXS might be transmitted in the families of the two individuals bearing the mutation, and that it is important to understand the mutation dynamics to provide better counseling to the family members of these two individuals.

Key words: Fragile X syndrome; Molecular diagnosis; Northeast Brazil; Mental disability

\section{INTRODUCTION}

Fragile X syndrome (FXS) is known as the most studied heritable intellectual disability in humans (Turner et al, 1996; Kooy et al., 2000). It is one of the first human diseases found to be associated with a mutation resulting from dynamic trinucleotide expansion; in FXS, the expansion occurs in the fragile $\mathrm{X}$ mental retardation 1 (FMR1) gene located on the $\mathrm{X}$ chromosome (Jin and Warren, 2000). FXS due to point mutations or deletions in the FMR1 gene has also been described but with less frequency (Coffee et al., 2008).

FXS represents approximately a third of inherited intellectual disability and is associated with behavioral, physical, and cognitive changes (Crawford et al., 2001; Terraciano et al., 2005). Its worldwide prevalence is about 1 in 3600 men and 1 in 8000 women (Turner et al, 1996; Kooy et al., 2000), and it is considered of great epidemiologic importance among men with mental disabilities (Webb et al., 1986).

FMR1 mutation is characterized by increased trinucleotide CGG repetitions in the 5'-untranslated region of the gene (Fu et al., 1991). This expansion of CGG tandem repeats in the first exon of the FMRI gene is the primary mutational event in FXS (Turner et al., 1996). The number of CGG repeats is polymorphic in the population; normal alleles present between 6-54 triplet repeats, with 30 being the number of repetitions found in most alleles (Jin and Warren, 2000; Bassell and Warren, 2008). Alleles with 55-200 repeats are considered premutated and are typically found in families with individuals diagnosed with FXS (Bassell and Warren, 2008). Individuals with FXS have more than 200 CGG repeats and, consequently, the promoter region of the gene including the region rich in CGGs becomes hypermethylated (Bassell and Warren, 2008). The methylation of the FMR1 gene results in a lack of transcription and a concomitant absence of the fragile $\mathrm{X}$ mental retardation protein in the brain, causing the clinical symptoms of FXS (Devys et al., 1993; Verheij et al., 1993).

In this study, we describe two cases of FMR1 mutation in males from specialized institutions in São Luís, Maranhão, Brazil.

\section{MATERIAL AND METHODS}

\section{Subjects}

Two hundred thirty-eight males with intellectual disability of unknown etiology par- 
ticipated in this study. This study was approved by the ethics committee of Hospital Universitário of Universidade Federal do Maranhão. It was initiated only after formal authorization from the participating institutions. The individuals who were legally responsible for the participants read and agreed with their participation by signing informed consents. The institutions with their respective numbers of participants are shown in Table 1.

Table 1. List of participating institutions.

\begin{tabular}{lc}
\hline Institution & Number of individuals \\
\hline Centro de Ensino de Educação Especial Padre João Mohana & 20 \\
Centro de Ensino de Educação Especial Helena Antipoff & 99 \\
APAE - Associação de Pais e Amigos dos Excepcionais de São Luís & 85 \\
Clínica La Ravardière de Neuropsiquiatria & 21 \\
Clínica São Francisco de Neuropsiquiatria & 13 \\
\hline
\end{tabular}

All subjects were previously diagnosed with intellectual disability. The individuals who were from special schools were diagnosed in public and private outpatient clinics before being sent to the schools and those from hospitals with the agreement of the Brazil's Unified Public Health System were diagnosed by neurologists and medical experts of their own institutions. Clinical evaluations were performed by the researcher under the guidance of a physician (psychiatrist) and a pediatrician.

The clinical records used were standardized by the Service of Human Genetics of Universidade do Estado do Rio de Janeiro. The records were comprised of the following features: seizures, attention deficit, hyperactivity, poor eye contact, tactile defensiveness, stereotyped behavior of hands, docility, rapid/repetitive speech, autistic behavior, hand-biting, mental disability, increased head circumference, elongated face, large ears, prominent forehead/jaw, pectus excavatum, ligamentous laxity, flat feet, simian crease, and macroorchidism. To measure the testicular volume we used a Praderorchidometer. The measures of the ears and the brain circumference were based on specific tables.

\section{Molecular diagnosis for FXS}

Blood collection was performed in the respective institutions with the assistance of a nurse technician. The samples were processed and stored at $-80^{\circ} \mathrm{C}$ until DNA extraction. We extracted DNA from the samples by using the commercial Illustra ${ }^{\mathrm{TM}}$ blood genomic prep mini spin kit (GE Healthcare, Little Chalfont, UK) following the manufacturer instruction.

Screening for FMR1 gene mutations was performed using the non-isotopic polymerase chain reaction (PCR) method described by Haddad et al. (1996). The primers used to amplify the 223-bp region (monomorphic control localized next to trinucleotide CGG repetitions in the 5'-untranslated region of the gene) and the polymorphic fragment of the CGG repeat are shown in Table 2.

Automated sequencing of the PCR product was conducted as a complementary analysis. Prior to sequencing, $20 \mu \mathrm{L}$ PCR product were purified using the AccuPrep PCR Purification Kit (Bioneer, Alameda, CA, USA) according to manufacturer protocol to remove residual oligonucleotides, dNTPs, enzymes, genomic DNA, and buffer components that were not used in the PCR. Sequencing was performed using an ABI Prism 3130 automated sequencer (Applied Biosystems). For evaluation of the electropherogram generated by the 
sequencing system we used the program Chromas Lite Version2.0 (Technelysium, South Brisbane, Australia) and for alignment of the patient sequences with their respective wildtype sequences we used the program Bioedit Sequence Alignment Editor Version 7.0.5.2 (Isis Pharmaceuticals, Inc., Carlsbad, CA, USA).

Table 2. Primers used in the PCR.

\begin{tabular}{ll}
\hline Primers & Sequence \\
\hline F & 5' - AGC CCC GCA CTT CCA CCA CCA GCT CCT CCA - 3' \\
U & 5' - CGA CCT GTC ACC GCC CTT CAG CCT TCC - 3' \\
L & 5' - CGC TGC GGG TGT AAA CAC TGAAAC CAC GTC - 3' \\
\hline
\end{tabular}

Primers and PCR conditions are presented as reported in Haddad et al., 1996. PCR = polymerase chain reaction.

\section{RESULTS}

In this study, 238 males aged 4 to 60 years (means \pm standard deviation: $21 \pm 9$ years) were analyzed for the presence of an FMR1 mutation. Most subjects were over 17 years old (64\%). Of all individuals tested, two $(0.84 \%)$ were positive for an FMR1 mutation. Individual 3503 had a mutation due to expansion of the CGG repeat above the normal level (Figure 1) and individual 3660 had a deletion in exon 1 of the FMR1 gene, flaking the CGG repeat region (Figure 2). The deletion was confirmed by sequencing.

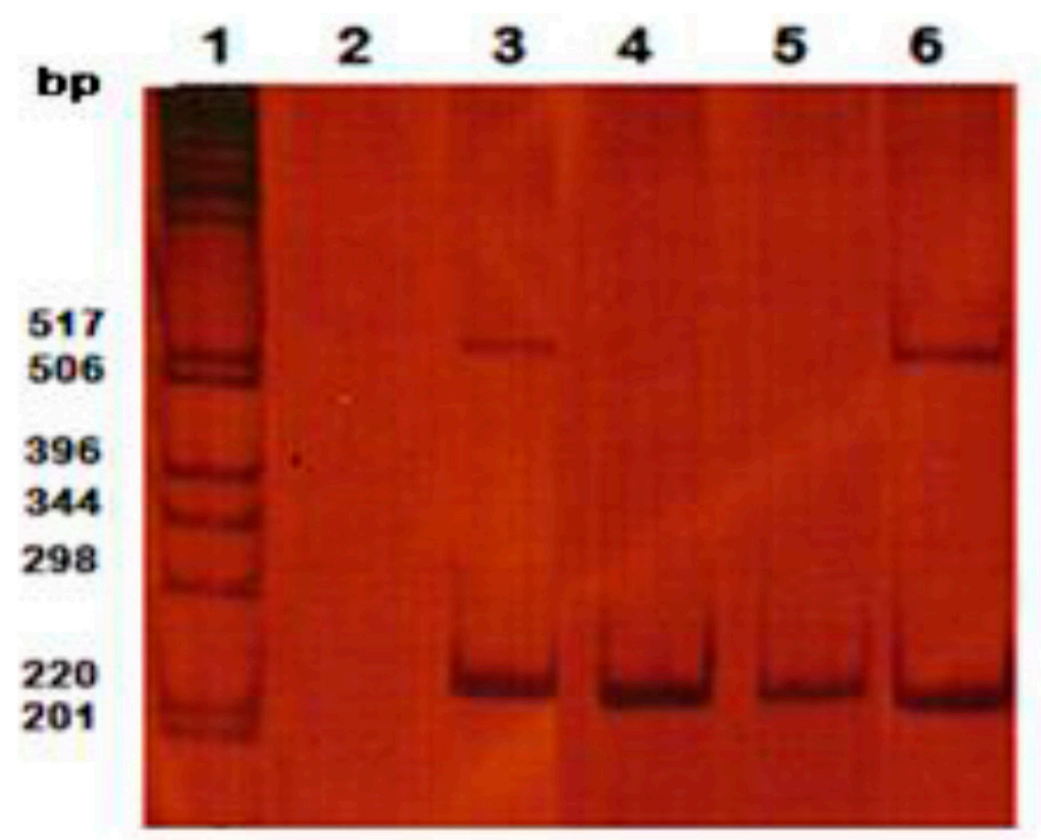

Figure 1. Polyacrylamide gel (5\%) showing the products from PCR amplification of four individuals. The lower band of $223 \mathrm{bp}$ represents the monomorphic control and the superior band of $550 \mathrm{bp}$ shows the amplification of products with CGG repets in normal individuals. Lane 1: molecular weight marker, $1 \mathrm{~kb}$; lane 2: negative control; lane 3: normal control; lane 4: positive control; lane 5: positive individual (3503); and lane 6: normal individual. PCR, polymerase chain reaction. 


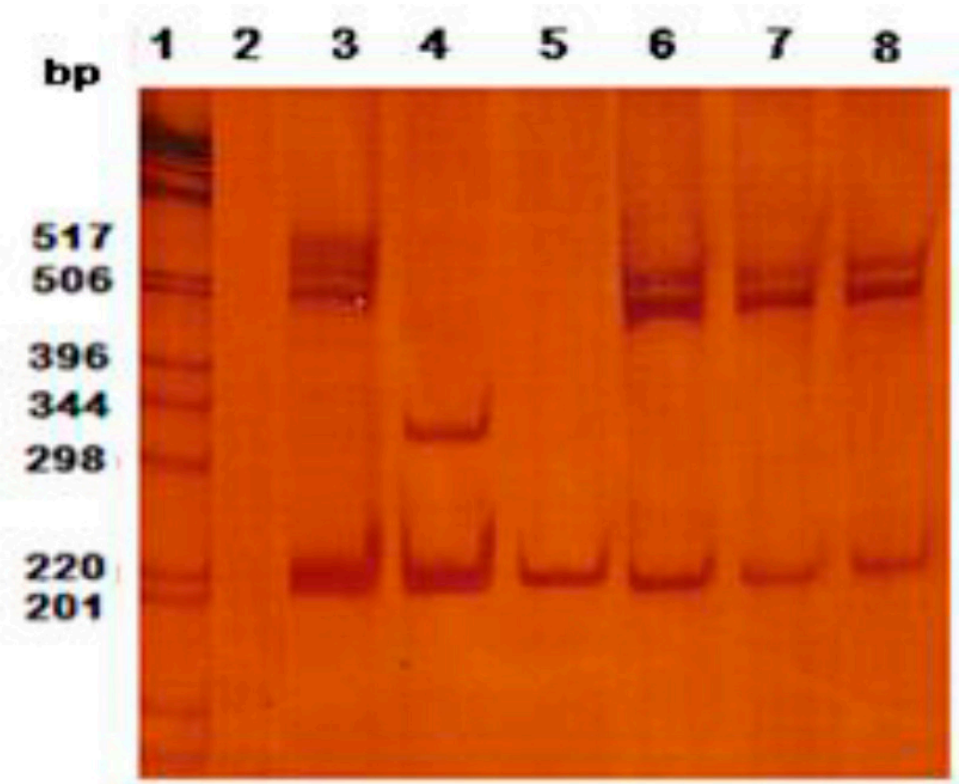

Figure 2. Polyacrylamide gel (5\%) showing the products from PCR amplification of six individuals. The lower band of $223 \mathrm{bp}$ represents de monomorphic control, the superior band of $550 \mathrm{bp}$ shows the amplification of products with CGG repets in normal individuals and the intemidiate band of around $330 \mathrm{bp}$ represents the deletion. Lane 1: molecular weight marker, $1 \mathrm{~kb}$; lane 2: negative control; lane 3: normal control; lane 4: individual (3660) with a deletion in the FMR1 gene; lane 5: positive control; and lanes 6, 7, and 8: normal individuals. PCR, polymerase chain reaction.

Individual 3503 was born through normal delivery and has no siblings. He had seizures in the first year of life and shows docile behavior, large ears, prominent jaw, and ligamentous laxity. His parents do not have cognitive problems (Figure 3). A photograph of individual 3503 can be seen in Figure 4.

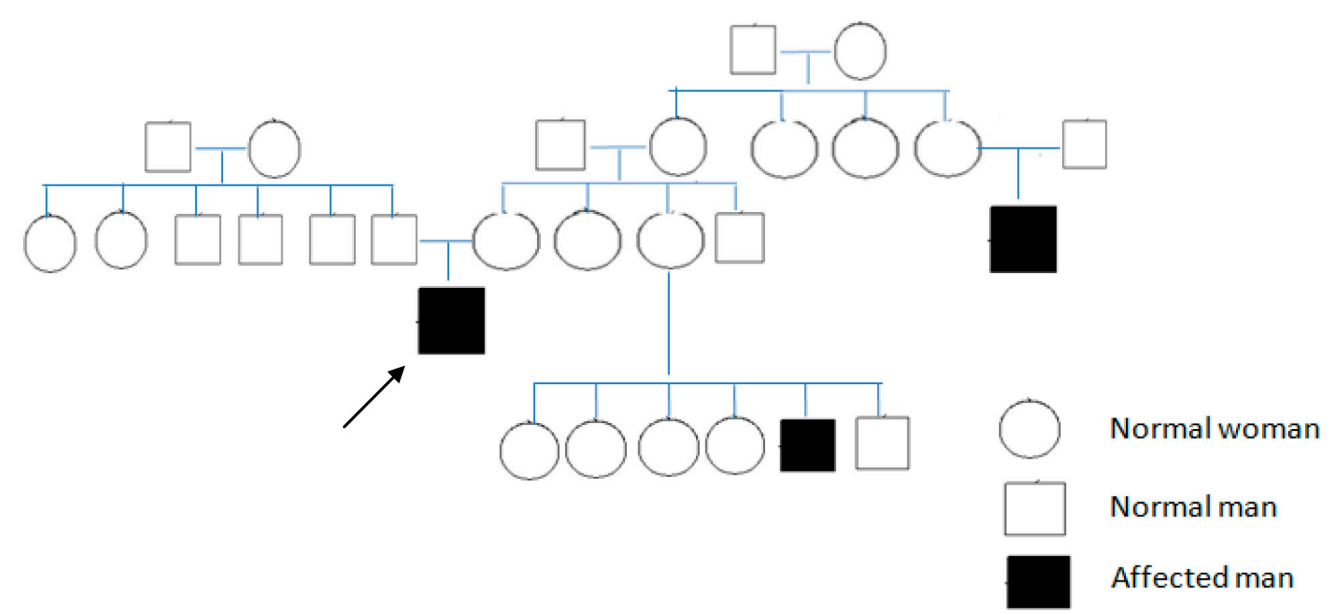

Figure 3. Pedigree of proband 3503 (arrow). Black squares indicate two additional male relatives with mental disability. 


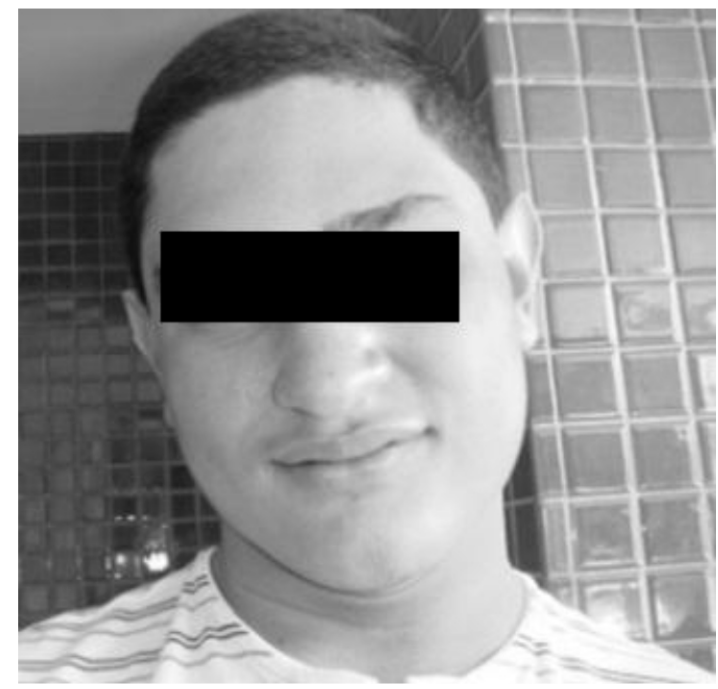

Figure 4. Individual 3503, who presented with a mutation in the FMR1 gene.

Individual 3660 was born through normal delivery and has no siblings. He was diagnosed as mentally disabled by a neurologist. He has repetitive speech, prominent head circumference, pectus excavatum, macroorchidism, poor eye contact, and large ears (Figure 5). His mother has mild mental retardation and his father presented signs of psychiatric problems (Figure 6).

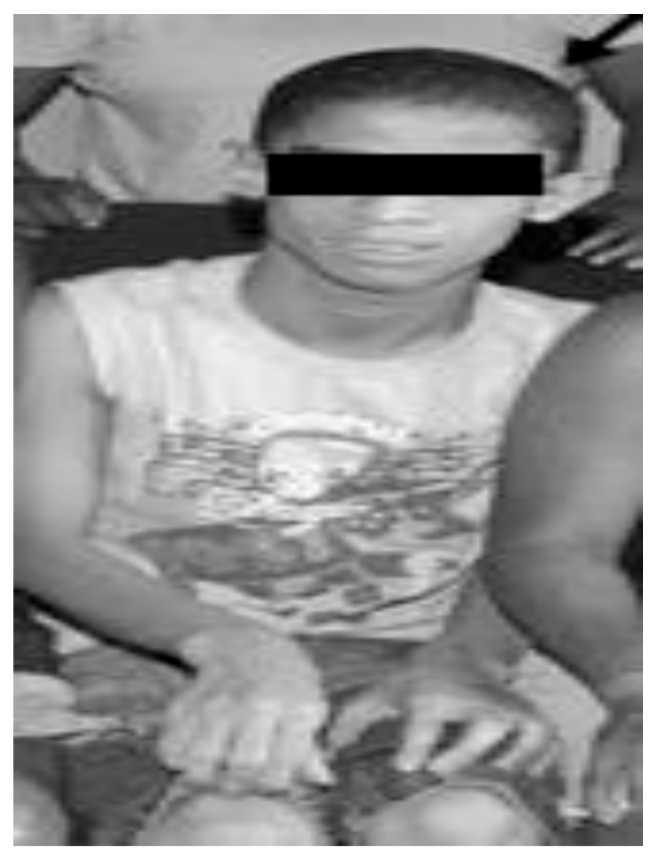

Figure 5. Individual 3660, who presented with a deletion in the FMR1 gene. 


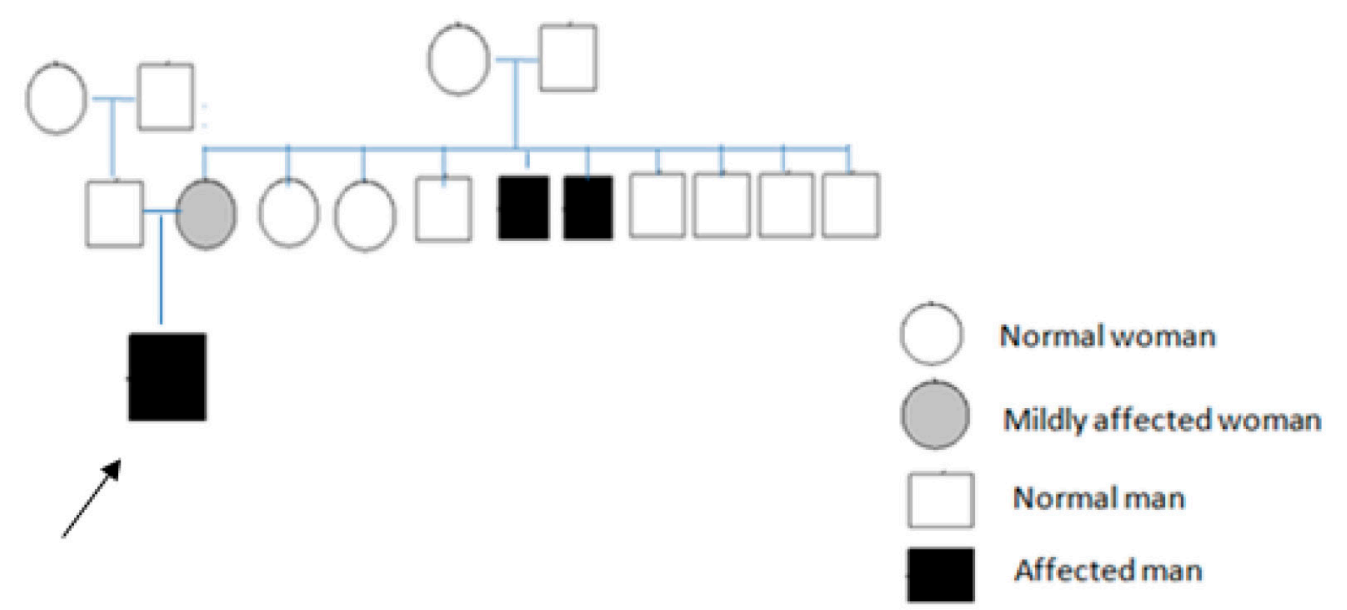

Figure 6. Pedigree of proband 3660 (arrow). Black squares represent the relatives with mental disability and gray indicates an individual with mild mental disability.

\section{DISCUSSION}

FXS is still an under-diagnosed disease in Brazil although it is recognized as a major cause of heritable mental disability (Turner et al, 1996; Kooy et al., 2000). To our knowledge, no studies regarding this syndrome have been published from Maranhão. However, the survey performed by Mingroni-Netto et al. (2002) examined the variability of CGG repeats in the FMR1 gene in populations of South America. In their study, they found a higher frequency of alleles with 30 CGG repeats in African Brazilian (including two communities in Maranhão), Amerindian, and Euro Brazilian individuals. Thus, this is the first study of FXS mutation screening performed in Maranhão.

We found great variability in the age of the individuals tested for FMRI mutation; however, the majority of individuals were older than 17 years (64\%). This finding illustrates the lack of programs in Maranhão aimed at diagnosing the causes of mental disability and, therefore, the lack of availability of clinical and/or educational interventions for individuals with intellectual disabilities and their families. It is known that the earlier these interventions are performed in parallel with genetic counseling the better the quality of life of the family will be as a whole. Studies have shown that about one third of children identified with FXS are not diagnosed before 10 years of age (Crawford et al., 2002).

We found two cases $(0.84 \%)$ of males with mutations in the FMR1 gene. Individual 3503 presented with expansion of more than 200 CGG repeats in the FRAXA locus and individual 3660 showed a deletion of approximately $197 \mathrm{bp}$ involving part of the CGG repeats and the flanking region. This prevalence of less than $1 \%$ for FXS mutations found in our study can be explained by the inclusion criteria, which allowed eligibility for all individuals with mental disability of unknown cause. It is known that there are no singular clinical symptoms specific for this syndrome, and that the combination of physical and behavioral symptoms increases the likelihood of an individual to have the disease (Wattendorf and Muenke, 2005). Several parameters based on physical characteristics and behavioral checklists have been gathered and used by clinicians for the pre-selection of individuals with mental disability eligible for 
molecular testing for FXS (Bailey et al., 2008). Studies that use such checklists in the clinical screening of mental disability achieve higher rates of FXS positive results. In our study, although we had assigned a checklist as a screening tool for FXS, we decided to include all individuals, previously diagnosed with intellectual disability by the physicians from the participating institutions, due to the small sample if we had considered eligible for screening only those with FXS features.

Nearly $95 \%$ of FXS is due to CGG expansion in the FMR1 gene (Penagarikano et al., 2007). However, several studies have described mutations involving deletion of the FMRI CGG repeat region and adjacent sequences (Garcia Arocena et al., 2000; Fan et al., 2005). It is possible that a not-insubstantial number of FXS cases might result from the deletion mechanism that was seen in our study, but it is difficult to make an accurate determination at this time since most of the techniques used in screening surveys evaluate only the gene region containing the CGG repeats (McConkie-Rosell et al., 2005). Our finding implies the need for a more complete investigation of individuals eligible for FXS screening.

In the pedigrees shown in Figures 3 and 6 we can see that both individuals with FMR1 mutations have a family history of mental disability that shows a typical pattern of $\mathrm{X}$-linkage. This demonstrates that the history of mental disability in the family is also an important feature in the selection of patients to be screened for FXS (Bailey et al., 2008). Unfortunately, this information was not included in the records of the institutions that participated in this study.

Thus, we observed that FXS might be transmitted in the families of the two individuals bearing the mutation, and that an understanding of these dynamics is important to provide better counseling for their family members.

\section{Conflicts of interest}

The authors declare no conflict of interest.

\section{ACKNOWLEDGMENTS}

Research supported by Fundação de Amparo à Pesquisa e Desenvolvimento Científico do Maranhão (FAPEMA). We also thank all the Institutions that participated in this study, the staff of Centro de Pesquisa Clínica do Maranhão (CEPEC), and the psychiatrist Geraldo Melonio do Nascimento for his help in the identifying the clinical characteristics of Fragile X Syndrome.

\section{REFERENCES}

Bailey DB Jr, Skinner D, Davis AM, Whitmarsh I, et al. (2008). Ethical, legal, and social concerns about expanded newborn screening: fragile X syndrome as a prototype for emerging issues. Pediatrics 121: e693-704.

Bassell GJ and Warren ST (2008). Fragile X syndrome: loss of local mRNA regulation alters synaptic development and function. Neuron 60: 201-214.

Coffee B, Ikeda M, Budimirovic DB, Hjelm LN, et al. (2008). Mosaic FMRI deletion causes fragile X syndrome and can lead to molecular misdiagnosis: a case report and review of the literature. Am. J. Med. Genet. A 146A: 1358-1367.

Crawford DC, Acuña JM and Sherman SL (2001). FMR1 and the fragile X syndrome: human genome epidemiology review. Genet. Med. 3: 359-371.

Crawford DC, Meadows KL, Newman JL, Taft LF, et al. (2002). Prevalence of the fragile X syndrome in AfricanAmericans. Am. J. Med. Genet. 110: 226-233.

Devys D, Lutz Y, Rouyer N, Bellocq JP, et al. (1993). The FMR-1 protein is cytoplasmic, most abundant in neurons and 
appears normal in carriers of a fragile X permutation. Nat. Genet. 4: 335-340.

Fan H, Booker JK, McCandless SE, Shashi V, et al. (2005). Mosaicism for an FMR1 gene deletion in a fragile X female. Am. J. Med. Genet. A 136: 214-217.

Fu YH, Kuhl DP, Pizzuti A, Pieretti M, et al. (1991). Variation of the CGG repeat at the fragile X site results in genetic instability: resolution of the Sherman paradox. Cell 67: 1047-1058.

Garcia Arocena D, de Diego Y, Oostra BA, Willemsen R, et al. (2000). A fragile X case with an amplification/deletion mosaic pattern. Hum. Genet. 106: 366-369.

Haddad LA, Mingroni-Netto RC, Vianna-Morgante AM and Pena SD (1996). A PCR based test suitable for screening for fragile X syndrome among mentally retarded males. Hum. Genet. 97: 808-812.

Jin P and Warren ST (2000). Understanding the molecular basis of fragile X syndrome. Hum. Mol. Genet. 9: $901-908$.

Kooy RF, Willemsen R and Oostra BA (2000). Fragile X syndrome at the turn of the century. Mol. Med. Today 6: $193-198$.

McConkie-Rosell A, Finucane B, Cronister A, Abrams L, et al. (2005). Genetic counseling for fragile X syndrome: updated recommendations of the national society of genetic counselors. J. Genet. Couns. 14: 249-270.

Mingroni-Netto RC, Angeli CB, Auricchio MT, Leal-Mesquita ER, et al. (2002). Distribution of CGG repeats and FRAXAC1/DXS548 alleles in South American populations. Am. J. Med. Genet. 111: 243-252.

Penagarikano O, Mulle JG and Warren ST (2007). The pathophysiology of fragile X syndrome. Annu. Rev. Genomics Hum. Genet. 8: 109-129.

Terracciano A, Chiurazzi P and Neri G (2005). Fragile X syndrome. Am. J. Med. Genet. C Semin. Med. Genet. 137C: 32-37.

Turner G, Webb T, Wake S and Robinson H (1996). Prevalence of fragile X syndrome. Am. J. Med. Genet. 64: $196-197$.

Verheij C, Bakker CE, de Graaff E, Keulemans J, et al. (1993). Characterization and localization of the FMR-1 gene product associated with fragile X syndrome. Nature 363: 722-724.

Wattendorf DJ and Muenke M (2005). Diagnosis and management of fragile X syndrome. Am. Fam. Physician 72: 111113.

Webb TP, Bundey SE, Thake AI and Todd J (1986). Population incidence and segregation ratios in the Martin-Bell syndrome. Am. J. Med. Genet. 23: 573-580. 